\title{
A Numerical Study of a Viscous flow Past a Circular Cylinder on an $f$-plane
}

\author{
By Tomonori Matsuura \\ Faculty of Engineering, Ibaraki University Nakanarusawa-machi 4-12-1, Hitachi 316, Japan \\ and Toshio Yamagata
}

Research Institute for Applied Mechanics, Kyushu University, Kasuga 816, Japan

(Manuscript received 24 October 1984, in revised form 5 January 1985)

\begin{abstract}
Numerical solutions of a homogeneous, incompressible and viscous flow past a circular cylinder on an $f$-plane are presented. A direct comparison is made between published experimental results and the numerical results and shown to be in good agreement. As observed experimentally by Boyer (1970) and Boyer and Davies (1982), the presence of the Ekman friction delays the boundary layer separation. This is because the Ekman friction alleviates the adverse pressure gradient at the surface of the cylinder. It is shown that the eddies initially formed behind the cylinder finally spin-down. The core of these eddies, in contrast to a non-rotating case, becomes almost stagnant in a final state. The drag coefficient $C_{d}$ is dependent on both $R_{e}$ and $\alpha$ where $\alpha$ is the ratio of the square root of the Ekman number to the Rossby number. It decreases as $R_{e}$ increases at least for $20 \leq R_{e} \leq 200$ when $\alpha$ is fixed. If $\mathrm{Re}$ is kept constant, $C_{d}$ increases with increasing $\alpha$. The Stokes's drag law adapted for a rotating fluid is found to be in good agreement with the present numerical result at a small Reynolds number. It is also found that a nonlinear effect $\left(O\left(R_{0}^{2}\right)\right)$ associated with the Ekman suction can generate a noticeable asymmetry (which was observed in the experiments) in the wake when separation occurs.
\end{abstract}

\section{Introduction}

A study of a flow past a rigid circular cylinder is one of the most basic and classical problems in fluid dynamics. However, we do not yet have a complete theory which covers the whole range of the Reynolds number $R_{e}$ ( $=2 U R / \nu$, where $U$ is the typical velocity, $R$ is the radius of the cylinder and $\nu$ is the kinematic viscosity). Therefore, laboratory experiments and/or numerical simulations are important aids for our understanding of the flow structures, especially at large Reynolds number. The detailed discussion in this fields can be found in the text book by Batchelor (1970).

The problem has been extended to a rotat- ing fluid since Proudman (1916) and Taylor (1917) observed the interesting phenomenon, which is now called the Taylor column, over an obstacle moving slowly in a rotating fluid. In the present paper we discuss flows past a circular cylinder in a rotating system bounded above and below by two infinite parallel planes. This problem is similar to the Taylor column problem but is much simpler than that. However, it is still complex compared to the original one in fluid dynamics because of the effect of rotation. In other words, our problem might be described as being located at the junction between conventional fluid dynamics and geophysical fluid dynamics (Yamagata, 1976).

Three nondimensional parameters come out 
in our system : Rossby number $R_{0}(=U / 2 \Omega R$, where $\Omega$ is the basic rotation rate), Ekman number $E_{k}\left(=\nu / \Omega H^{2}\right.$, where $H$ is the depth of the fluid) and the aspect ratio $\delta(=H / R)$. Boyer (1970) and Boyer and Davies (1982) conducted an intriguing series of laboratory experiments in the present field of work. The main conclusion relevant to the present paper is that the suppression of the relative vorticity by the Ekman friction delays the onset of separation. They provided the detailed diagrams which classify the flow patterns into fully attached ones (see Fig. 2a) and detached ones (see Figs. 2b, c). They also showed the relationship between the size of a separated eddy and above nondimensional values. Our motive is to clarify underlying physics by comparing numerical results with their experimental results. By using the boundary layer approximation, Merkine and Solan (1979) recently investigated the separation of streamlines from the cylinder on an $f$-plane. Their main conclusion is that the boundary layer separation is strongly dependent on the parameter $\alpha\left(=E_{k}^{1 / 2} / R_{0}\right)$. Merkine and Solan (1979) showed that the asymmetric pattern in the wake (which was observed by Boyer (1970)) was due to the relative vorticity generated by the Ekman divergence on the left hand side of the cylinder or convergence on the right hand side of the cylinder facing downstream. Namely, they showed that the asymmetry of the separation points becomes more pronounced as the Rossby number increases. The same idea was also suggested by Walker and Stewartson (1972).

The present paper aims mainly to clarify the following four points.

(i) How does the flow pattern change as the above nondimensional parameters are changed? Is it possible to simulate the flow patterns observed in the laboratory experiments? In particular, we pay attention to the role played by the Ekman friction.

(ii) How do the viscous dissipation by the Ekman friction and the lateral friction change the drag coefficient $C_{d}$ ? Namely, we examine the dependence of $C_{d}$ on $\alpha$ and $R_{e}$.

(iii) How does the Ekman friction affect the eddies behind the cylinder after they are formed?

(iv) What is the role played by the nonlinear effect associated with the Ekman suction? Is it possible to explain the observed asymmetry in the wake within the framework of the quasi-geostrophic approximation?

We restrict our parameter range within $R_{0}<O(1), E_{k} \ll O(1)$ and $\delta=2$. Under these conditions we derive the quasi-geostrophic equation in $\S 2$. Even if $R_{0}$ is small in our analysis, the nonlinear advection of vorticity cannot be neglected for $R_{e}>O(1)$ and $\alpha<O(1)$. Therefore, the quasi-geostrophic potential vorticity equation, derived in $\S 2$, is integrated numerically from the initial state which is a potential flow around the circular cylinder with respect to a rotating frame. In $\S 3$, a steady linear solution is presented to clarify the relative importance of the advection term. It is shown that the Stokes's solution is uniformly valid in space in contrast to that of the non-rotating fluid. The numerical method is described in $\S 4$. The results of numerical calculations for a uniform basic flow (flow and vorticity patterns, drag coefficient and spin-down of eddies behind the cylinder) are presented in $\S 5$. In $\S 6$, the nonlinear effect associated with the Ekman suction is discussed in connection with the asymmetric property of the wake. A summary is given in the final section.

\section{Mathematical formulation}

We study the flow past a circular cylinder in a rotating fluid (Fig. 1). The cylinder has radius $R$ and height $H$. The whole system rotates with a constant angular velocity $\Omega$ parallel to the axis of the cylinder. The fluid has constant density $\rho$ and constant kinematic viscosity $\nu$. It is assumed that the basic flow, unbounded laterally (in a horizontal plane), has the uniform velocity $U$ in the direction of $\theta=0$. Hereafter the velocity components relative to the rotating frame are denoted by $\left(u_{r}, u_{\theta}, w\right)$ with corresponding cylindrical polar coordinates $(r, \theta, z)$, the pressure is denoted by $p$ and the time is denoted by $t$. We introduce the following nondimensional 


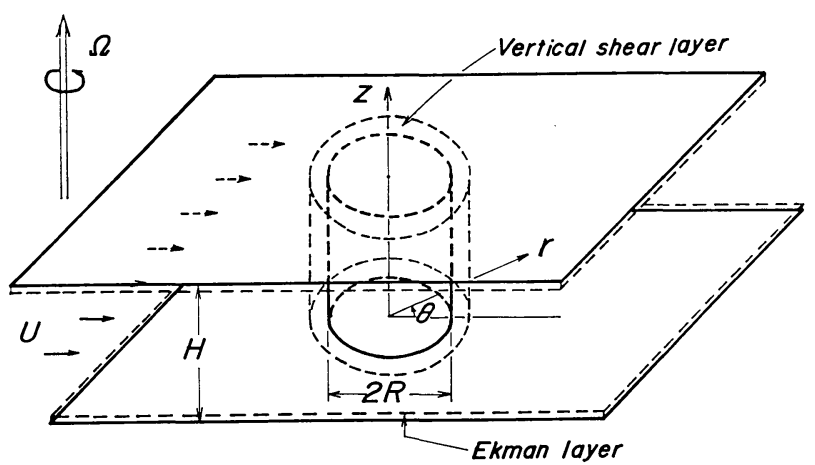

Fig. 1 Schematic representation of the flow configuration.

quantities denoted by the asterisk,

$$
\begin{cases}\boldsymbol{V}_{h}=U\left(u_{r}^{*}, u_{\theta}^{*}\right) & w=U \frac{H}{R} w^{*} \\ r=R \cdot r^{*} & z=H \cdot z^{*} \\ \dot{t}=\frac{R}{U} t^{*} & p=-\rho g z^{*}+2 \rho U \Omega R p^{*}\end{cases}
$$

The nondimensional momentum and continuity equations are then, dropping the asterisk,

$$
\begin{aligned}
& R_{0} \frac{D \boldsymbol{V}}{D t}+\hat{\boldsymbol{k}} \times \boldsymbol{V} \\
& \quad=-\boldsymbol{\nabla} p+\frac{E_{k}}{2}\left(\delta^{2} \boldsymbol{\nabla}_{h}^{2} \boldsymbol{V}+\frac{\partial^{2} \boldsymbol{V}}{\partial z^{2}}\right), \\
& \nabla \cdot \boldsymbol{V}=0 .
\end{aligned}
$$

where $\hat{\boldsymbol{k}}$ is the $z$-component unite vector and $\boldsymbol{\nabla}_{h}^{2}$ is the two-dimensional Laplacian. The nondimensional parameters $R_{0}$ (the Rossby number), $E_{k}$ (the Ekman number) and $\delta$ (the aspect ratio) governing the flow are defined as follows :

$$
R_{0}=U / 2 \Omega R, \quad E_{k}=\nu / \Omega H^{2}, \quad \delta=H / R .
$$

The boundary conditions for the velocity fields are

$$
\begin{array}{ll}
u_{r}=u_{\theta}=w=0 & \text { at } \quad r=1, \\
u_{r}=u_{\theta}=w=0 & \text { at } \quad z=0,1,
\end{array}
$$

and

$$
\left(u_{r}, u_{\theta}\right)=(\cos \theta,-\sin \theta) \quad \text { as } \quad r \rightarrow \infty .
$$

The range of parameters discussed in the present study is

$$
R_{0}<O(1), E_{k} \ll O(1),
$$

and

$$
\delta=2 .
$$

For convenience we introduce another parameter $\alpha$ defined by

$$
\alpha=2 E_{k}^{1 / 2} /\left(R_{0} \cdot \delta\right) .
$$

Since the above parameter denotes the ratio of the advective time scale $(2 R / U)$ to spindown time scale $\left(H /(\nu \Omega)^{1 / 2}\right)$, the spindown time is shorter than the time needed for the vorticity generated around the cylinder to be advected away for $\alpha>1$, and vice verse for $\alpha<1$.

From Eqs. (2.2) we can derive the $z$-component of relative vorticity equation:

$$
\begin{aligned}
\frac{D \zeta}{D t}= & \left\{\zeta \frac{\partial w}{\partial z}+\left(\frac{1}{r} \frac{\partial w}{\partial \theta} \cdot \frac{\partial u_{r}}{\partial z}-\frac{\partial w}{\partial r} \cdot \frac{\partial u_{\theta}}{\partial z}\right)\right\} \\
& +R_{0}^{-1} \frac{\partial w}{\partial z}+\frac{E_{k}}{2 R_{0}}\left\{\delta^{2} \nabla_{h}^{2} \zeta+\frac{\partial^{2} \zeta}{\partial z^{2}}\right\},
\end{aligned}
$$

where $\zeta=\frac{1}{r} \cdot \frac{\partial\left(r u_{\theta}\right)}{\partial r}-\frac{1}{r} \frac{\partial u_{r}}{\partial \theta}$. For $R_{0}<O(1)$ and $E_{k} \ll O(1)$ a solution must satisfy, to the lowest order, the inviscid geostrophic equation,

$$
\boldsymbol{k} \times \boldsymbol{V}=-\nabla p,
$$

Thus we can introduce the geostrophic stream function $\Psi$, which corresponds to the lowest order pressure $p^{(0)}$, for the interior flow :

$$
u_{r}^{(0)}=-\frac{1}{r} \cdot \frac{\partial \Psi}{\partial \theta},
$$




$$
u_{\theta}^{(0)}=\frac{\partial \Psi}{\partial r} .
$$

Since $u_{r}^{(0)}, u_{\theta}^{(0)}$ and $p^{(0)}$ are independent of $z$ from (2.7), $w^{(0)}$ is constant in $z$ from (2.2b). From the boundary condition $(2.3 \mathrm{~b}) w^{(0)}$ should vanish and the vorticity equation (2.6) is, to $O\left(R_{0}\right)$,

$$
\begin{gathered}
\frac{\partial \zeta^{(0)}}{\partial t}+u_{r}^{(0)} \frac{\partial \zeta^{(0)}}{\partial r}+\frac{u_{\theta}^{(0)}}{r} \frac{\partial \zeta^{(0)}}{\partial \theta} \\
=\frac{\partial w^{(1)}}{\partial z}+\frac{2}{R_{0}} \nabla_{h}^{2} \zeta^{(0)}
\end{gathered}
$$

where the relative vorticity $\zeta^{(0)}$ is defined as follows

$$
\zeta^{(0)}=\nabla_{h}^{2} \Psi .
$$

The nondimensional parameter $R_{e}(=2 R U / \nu=$ $\left.4 R_{0} /\left(E_{k} \delta^{2}\right)=4 /\left(\alpha \cdot E_{k}^{1 / 4} \delta^{2}\right)\right)$ is the Reynolds number. The lateral diffusion term is assumed to be $O(1)$ at most and retained at the present stage.

Since we assume $\alpha \sim O(1)$, analysis of the Ekman layers on $z=0,1$ leads to the compatibility conditions (Greenspan 1968)

$$
R_{0} w^{(1)}(r, \theta, 0)=\frac{E_{k}^{1 / 2}}{2} \zeta^{(0)} \quad \text { on } \quad z=0 \text {. }
$$

A similar analysis on $z=1$ leads to

$$
R_{0} w^{(1)}(r, \theta, 1)=-\frac{E_{k}^{1 / 2}}{2} \zeta^{(0)} \quad \text { on } \quad z=1 .
$$

Finally, the vorticity equation (2.9a) is reduced to

$$
\frac{\partial \zeta}{\partial t}+J(\Psi, \zeta)=-\alpha \zeta+\frac{2}{R_{e}} \nabla_{h}^{2} \zeta
$$

where $J$ is the two-dimensional Jacobian and the lowest order relative vorticity is simply denoted by $\zeta$. The first term on the lefthand side of Eq.(2.11) denotes the Eulerian time change of the relative vorticity and the second term denotes the nonlinear advection of the relative vorticity. The first term on the right-hand side denotes the viscous dissipation by the Ekman friction and the second term denotes the lateral diffusion. Since the lateral diffusion is added, Eq.(2.11) is not the conventional quasi-geostrophic equation. The inclusion of this term enables us to treat the vertical shear layers in the simplest way. As is clear in the derivation, the lowest order balance in these layers is assumed to be geostrophic. The boundary conditions are now reduced

$$
\Psi=\frac{\partial \Psi}{\partial r}=0 \quad \text { at } \quad r=1,
$$

and

$$
\Psi=-r \sin \theta \quad \text { as } \quad r \rightarrow \infty .
$$

Now the quasi-geostrophic flow is determined by Eqs. (2.9b) and (2.11), subject to the boundary conditions in (2.12). Numerical solutions are obtained using the finite difference method. The description of the method is described in $\$ 4$.

Before going into the details of our results, one should point out that Eq.(2.11) is consistent within the framework of the quasigeostrophic approximation. The inclusion of the lateral diffusion requires, from Eq.(2.11)

$$
\alpha \geqq 1 /\left(R_{e} L_{H}^{2}\right),
$$

where $L_{H}$ denotes the nondimensional lateral thickness of the vertical boundary layer around the cylinder. The above inequality is simply reduced to

$$
L_{I I} \geqq E_{k}^{1 / 4} .
$$

Notice here that $E_{k}^{1 / 4}$ corresponds to the thickness of a linear $E_{k}^{1 / 4}$-Stewartson layers (Stewartson, 1957), which is much larger than that of the Ekman layer. Therefore, if the condition (2.13) is satisfied, one can adopt the Ekman layer solution even within the vertical boundary layer. Equation (2.11) is derived within the conventional quasi-geostrophic approximation in that sense. A careful inspection, however, shows that two vertical boundary layers $\left(E_{k}^{1 / 3}\right.$-layer and $E_{k}^{1 / 4}$-layer $)$ are involved in the present problem (cf. Greenspan, 1968). One of thickness $E_{k}^{1 / 3}$ is necessary to satisfy the Ekman transport requirements. The other of thickness $E_{k}^{1 / 4}$ appears whenever an adjustment in lateral velocity tangential to a solid boundary is necessary. We neglect the role played by the $E_{k}^{1 / 3}$-layer 
in Eq. (2.11) partly because we expect the effect on the global flow structures is weak, and mainly because our purpose in the present paper is to examine whether the simplified equation (2.11) explains almost all basic flow structure observed in the laboratory experiments.

Merkine and Solan (1979) discussed the flow past a cylinder by including a nonlinear effect on the Stewartson layer. Since they took the relative vorticity generated by the Ekman divergence (on the left hand side of the cylinder facing downstream) into account, they could show the asymmetric property of vertical boundary layers relative to the flow direction. Here we need some comments on the use of this nonlinear effect. For $R_{0}<$ $O\left(E_{k}^{1 / 4}\right)$, one can use the linear Ekman condition (Eq. (2.10a, b)). For values of $R_{0}$ of order $E_{k}^{1 / 4}$ or larger, one should use the nonlinear Ekman condition (see Bennetts and Hocking 1973). However, we adopt tentatively the linear Ekman condition even if $R_{0} \sim O\left(E_{k}^{1 / 4}\right)$ (cf. Hide 1968; Barcilon 1970). In the present study we limit our argument mainly within the parameter space where the quasi-geostrophic approximation is consistent to $O\left(R_{0}\right)$ except for Section 6 .

\section{Steady linear solution}

In order to estimate the relative importance of nonlinear advection the linear viscous problem is discussed in this section. For $\left(R_{e} / 2 \alpha\right)^{1 / 2}$ $\ll 1$, the steady version of the quasi-geostrophic equation (2.11) is reduced to a linear equation

$$
\nabla_{h}^{4} \Psi-\lambda^{2} \nabla_{h}^{2} \Psi=0,
$$

where $\lambda^{2}=E_{k}^{-1 / 2} / 2\left(=\alpha R_{e} / 2\right)$. The boundary conditions are reduced to

$$
\left\{\begin{array}{l}
\Psi=0 \\
\frac{\partial \Psi}{\partial r}=0
\end{array} \quad \text { at } \quad r=1\right.
$$

and

$$
\Psi=-r \sin \theta \quad \text { as } \quad r \longrightarrow \infty .
$$

The solution is given by

$$
\begin{aligned}
\Psi(r, \theta)= & \left(-r+\frac{K_{2}(\lambda)}{K_{0}(\lambda)} \cdot \frac{1}{r}-\frac{2}{\lambda} \frac{K_{1}(\lambda r)}{K_{0}(\lambda)}\right) \\
& \times \sin \theta,
\end{aligned}
$$

where $K_{n}$ denotes the modified Bessel function of order $n$. In terms of vorticity, the solution is simply reduced to

$$
\zeta(r, \theta)=-2 \lambda-\frac{K_{1}(\lambda r)}{K_{0}(\lambda)} \sin \theta
$$

The flow is symmetric about $\theta=0$ and $\theta=$ $\pi / 2$. Equation (3.4) shows that the vorticity distribution is more confined around the cylinder in the case which has the larger value of $\lambda$. This is because the effect of Ekman friction is stronger as $\lambda$ becomes large. In other words, the width of the $E_{k}^{1 / 4}$-Stewartson boundary layer is inversely proportional to $\lambda$.

It remains to verify whether the solution (3.3) is valid uniformly in space or not. The magnitude of viscous term $\left(-\alpha \zeta+\left(2 / R_{e}\right) \nabla^{2} \zeta\right)$ is $O\left(\lambda \alpha \frac{K_{1}(\lambda r)}{K_{0}(\bar{\lambda})}\right)$, whereas that of the neglected inertia term $(\boldsymbol{u} \cdot \nabla \zeta)$ is $O\left(\lambda^{2} \frac{K_{0}(\lambda r)}{K_{0}(\lambda)}\right)$. Thus the ratio of these two terms is, symbolically,

$$
\frac{\text { inertia term }}{\text { viscous term }} \sim\left(\frac{R_{e}}{2 \alpha}\right)^{1 / 2} \cdot \frac{K_{0}(\lambda r)}{\bar{K}_{1}(\overline{\lambda r})}
$$

As $r \rightarrow \infty$, the above ratio tends to $\left(R_{e} / 2 \alpha\right)^{1 / 2}$. Therefore, if $\left(R_{e} / 2 \alpha\right)^{1 / 2}$ is much less than unity, the inertia force can be neglected everywhere to the lowest approximation. In other words, "Stokes's paradox" disappears [in a rotating fluid. Thus we need not to introduce the Oseen approximation (cf. Batchelor, 1970) to describe the outer field in a rotating fluid. The drag coefficient $C_{d}$ is given by

$$
\begin{aligned}
C_{d} & =\frac{4 \lambda^{2}}{R_{e}} \pi\left[1+\frac{2}{\lambda} \cdot \frac{K_{1}(\lambda)}{K_{0}(\lambda)}\right] \\
& =2 \alpha \pi\left[1+\frac{2 \sqrt{2}}{\sqrt{\alpha}} \cdot \overline{\overline{R_{e}}} \cdot \frac{K_{1}\left(\sqrt{\left.\alpha R_{e} / 2\right)}\right.}{K_{0}\left(\sqrt{\left.\alpha \bar{R}_{0} / \overline{2}\right)}\right.}\right],
\end{aligned}
$$

where the details of the drag calculation are shown in Appendix A. The above formula may be called as the modified Stokes's law 
in a rotating fluid. The dashed lines for $\alpha$ $\neq 0$ in Fig. 7 are estimated based on (3.6) and are in close agreement with the numerical results at a small Reynolds number.

\section{Numerical method}

The flow governed by Eqs. (2.9b) and (2.11), subject to the boundary conditions in (2.12), was calculated numerically using a procedure similar to that given in the classical paper by Kawaguti and Jain (1966). To resolve the vertical boundary layers we introduce new independent variables $(\xi, \eta)$ instead of $(r, \theta)$, namely,

$$
\begin{aligned}
& \xi=\ln r, \\
& \eta=\theta .
\end{aligned}
$$

Formally we separate the streamfunction $\Psi$ into the basic part and the perturbed part $\phi$. That is

$$
\Psi=-r \sin \theta+\phi
$$

Consequently Eqs.(2.11) and (2.9b) takes the forms

$$
\begin{aligned}
& \left.\frac{\partial \zeta}{\partial t}+e^{-2 \xi} \frac{\partial(\phi, \zeta)}{\partial(\xi,}, \eta\right)+e^{-\xi}\left(\frac{\partial \zeta}{\partial \xi} \cos \eta-\frac{\partial \zeta}{\partial \eta} \sin \eta\right) \\
& =-\alpha \zeta+\frac{2}{R_{e}} \cdot e^{-2 \xi} \Delta \zeta,
\end{aligned}
$$

and

$$
\zeta=e^{-2 \xi} \Delta \psi,
$$

where $\Delta$ denotes the two-dimensional Laplacian in $(\xi, \eta)$-coordinates. For $t<0$, the fluid is at rest with respect to the rotating frame. The mean flow is impulsively switched on at $t=0$. Therefore the initial and boundary conditions are given by

$$
\psi=e^{\xi} \sin \eta \quad \text { and } \zeta=0 \quad(t<0),
$$

and

$$
\begin{aligned}
& \psi \longrightarrow 0 \quad \text { as } \xi \longrightarrow \infty \quad(t>0), \\
& \psi=\frac{\partial \psi}{\partial \xi}=\sin \eta \quad \text { at } \quad \xi=0
\end{aligned}
$$

In order to solve the vorticity equation (4.3a), we adopt a forward difference scheme for the time derivative and centered differences for the space derivatives. The Poisson equation (4.3b) is solved using the conventional successive overrelaxation method. The domain of calculation is a circle of which radius is one hundred times as large as that of the cylinder. The $45 \times 60(0 \leq \eta \leq 2 \pi)$ or $89 \times 60(0 \leq \eta \leq \pi)$ polar grid points are used. The azimuthal grid points are regularly spaced. The radial grid points are also regularly spaced in $\xi$ but not in $r$. The grid size $\Delta h$ in $(\xi, \eta)$-coordinates is $1.0472 \times 10^{-1}(=2 \pi / 60)$ or $5.236 \times 10^{-2}$ $(=\pi / 60)$. Roughly speaking, at least three radial mesh points exist in the linear Stewartson layer. The additional experiment which had at least five mesh points in the Stewartson layer was performed to check the resolution. The truncation errors in our numerical approach are $O\left(\Delta h^{2}\right)$ in space $(O(\Delta h)$ on the circular cylinder) and $O(\Delta t)$ in time. Numerical calculations were carried out for the following parameter space

$$
20 \leqq R_{e} \leqq 400, \quad 5 \times 10^{-2} \leqq \alpha \leqq 3.0 . \quad(4.5)^{*}
$$

The different temporal grid scale was adopted such as $4.0 \times 10^{-2}\left(40<R_{e} \leqq 200\right)$ and $2.0 \times 10^{-2}$ $\left(R_{e} \leqq 40\right)$ for $\Delta h=1.0472 \times 10^{-1}$. It was $2.0 \times$ $10^{-2}\left(R_{e}=200\right.$ and 400$)$ for $\Delta h=5.236 \times 10^{-2}$.

A test experiment without the Ekman friction was planned to examine our numerical scheme and found to be almost identical to the non-rotating results obtained by Kawaguti and Jain (1966).

\section{Results of numerical integration in the case of a uniform flow}

\subsection{Streamlines and lines of constant relative vorticity}

Figure 2 shows the comparison between the steady results of present numerical experiments** and those of laboratory experiments conducted by Boyer (1970). In both experiments $E_{k}$ was fixed and $R_{0}$ was changed.

* Numerical experiments are performed even for $\alpha \ll 0$ (1) although (2.11) is derived for $\alpha \sim 0(1)$. This is partly because the limit of $\alpha=0$ corres. ponds to the non-rotating two-dimensional case and mainly because we examine whether the simplified equation (2.11) explains the observed flow structures.

**The steadiness of the numerical results was judged by calculating a total drag in each case. Normally solutions become steady up to $T=40$. 

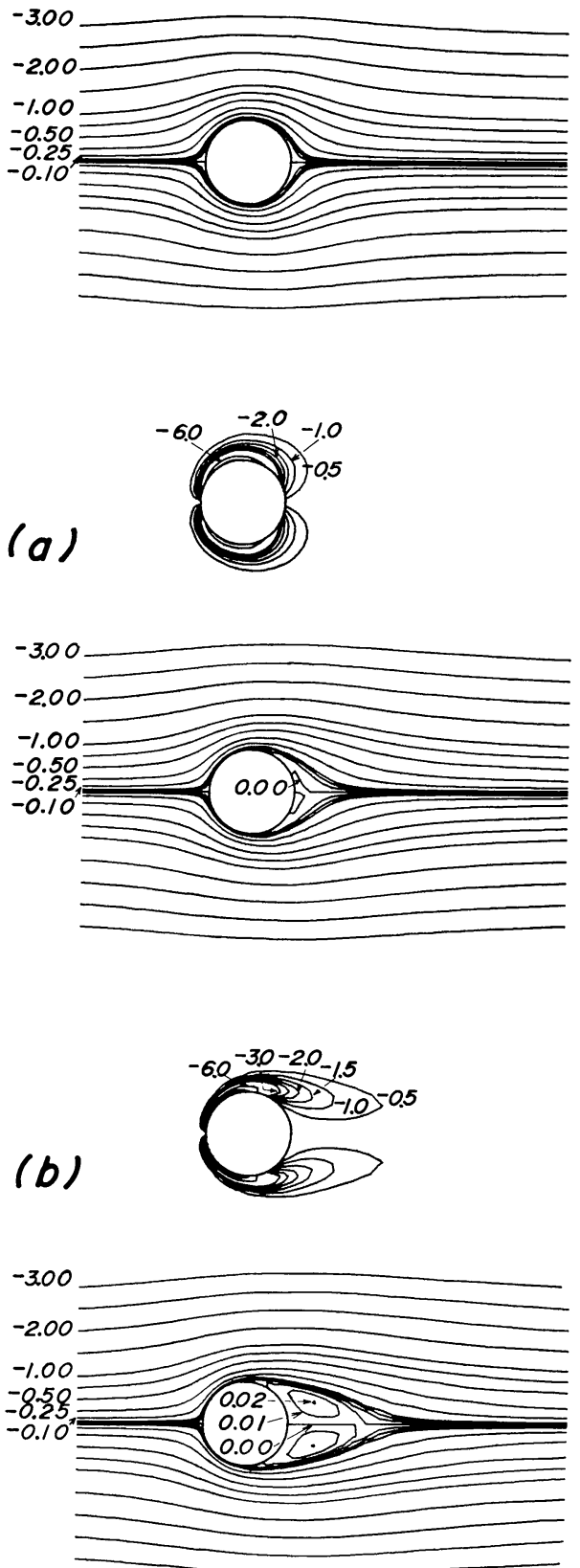

(c)

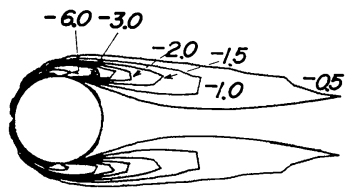

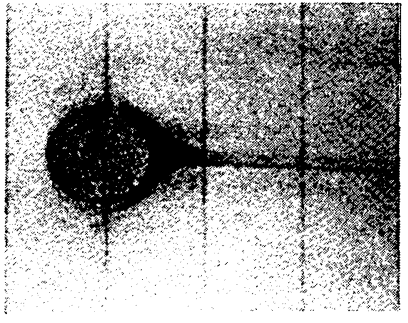
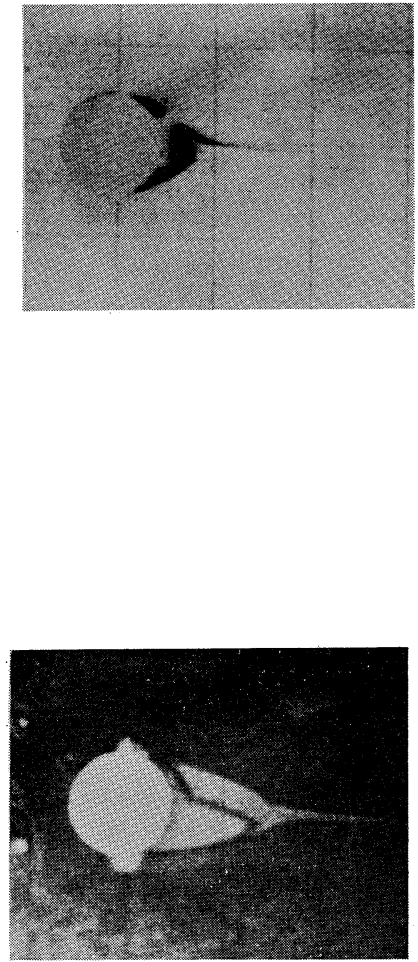

Fig. 2 (a) Simulated streamlines and lines of constant relative vorticity for $E_{k}=$ $8.6 \times 10^{-4}$ and $R_{0}=2.0 \times 10^{-2}$ (left panel) $\left(R_{e}=23.3, c:=1.47\right)$ and streamlines cited from Boyer (1970) (right panel). (b) As in (a), except that $R_{0}=1.0 \times 10^{-1}\left(R_{e}=\right.$ 116, $\alpha=0.293)$. (c) As in (a), except that $R_{0}=2.2 \times 10^{-1} \quad\left(R_{e}=256, \alpha=0.133\right)$. 

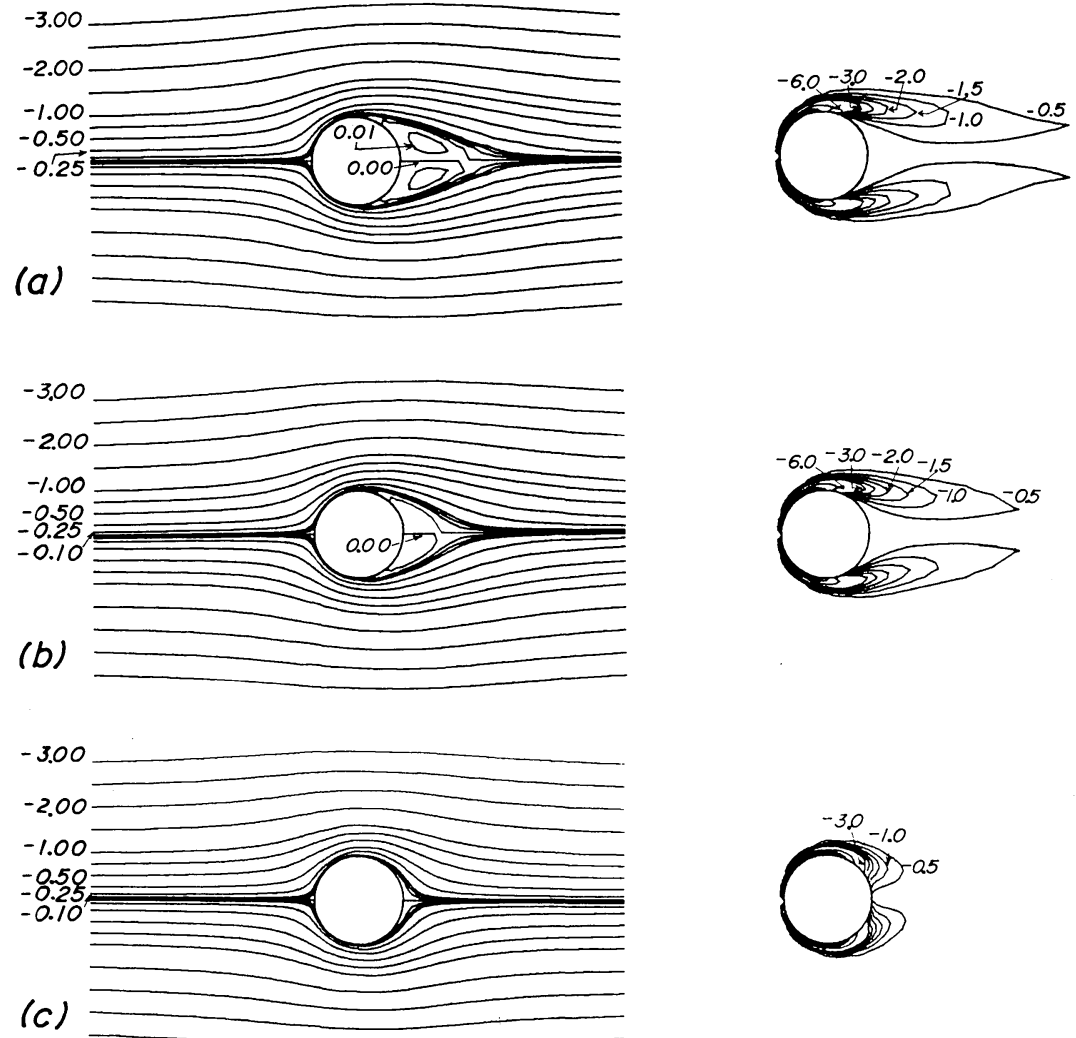

Fig. 3 (a) Streamlines and lines of constant relative vorticity for $R_{e}=200$ and $\alpha=0.158\left(E_{k}=1.0 \times 10^{-3}, R_{0}=2.0 \times 10^{-1}\right)$. (b) As in (a), except that $\alpha=0.224$ $\left(E_{k}=5.0 \times 10^{-4}, R_{0}=1.0 \times 10^{-1}\right)$. (c) As in (a), except that $\alpha=1.0 \quad\left(E_{k}=2.5 \times\right.$ $\left.10^{-5}, R_{0}=5.0 \times 10^{-3}\right)$.

The present study enables a clear comparison between the numerical results and the laboratory results despite a relatively severe limitation on the magnitude of $\alpha$ arising from the derivation of (2.11). In particular, the calculated length of the standing eddies behind the cylinder is almost equal to that visualized by Boyer (1970) (Fig. 2c). Both results show that, as $R_{0}$ increases and the advection of relative vorticity becomes more effective than the dissipative processes (the Ekman friction and the lateral diffusion of relative vorticity), the vertical boundary layer in front of the cylinder becomes thinner and more and more relative vorticity is carried round to the rear of the cylinder. This property is quite similar to that of the non-rotating case (cf. Batchelor 1970). It should be noted, however, that the streamline pattern similar to the non- rotating case is realized at a value of $R_{e}$ much larger than that of the corresponding non-rotating case. For example, Fig. 2c (which corresponds to $R_{e} \sim 200$ ) is very similar to the nonrotating case realized at $R_{e} \sim 20$ (see Taneda 1956 ; Batchelor 1970).

Figure 3 shows dependence of the numerical results on the parameter $\alpha$ (where $R_{e}$ is fixed at 200). In other words, the present series of experiments aim to clarify the role played by the Ekman friction. As $\alpha$ increases*, the wake behind the cylinder reduces its size; the Ekman friction suppresses development of the wake behind the cylinder. It is also remarkable that the streamline pattern

* Note that the increase of $\alpha$ is achieved by the relatively small decrease of $\mathrm{Ek}^{1 / 2}$ compared to the decrease of $R_{0}$ in the experiment with fixed $R_{e}$. 

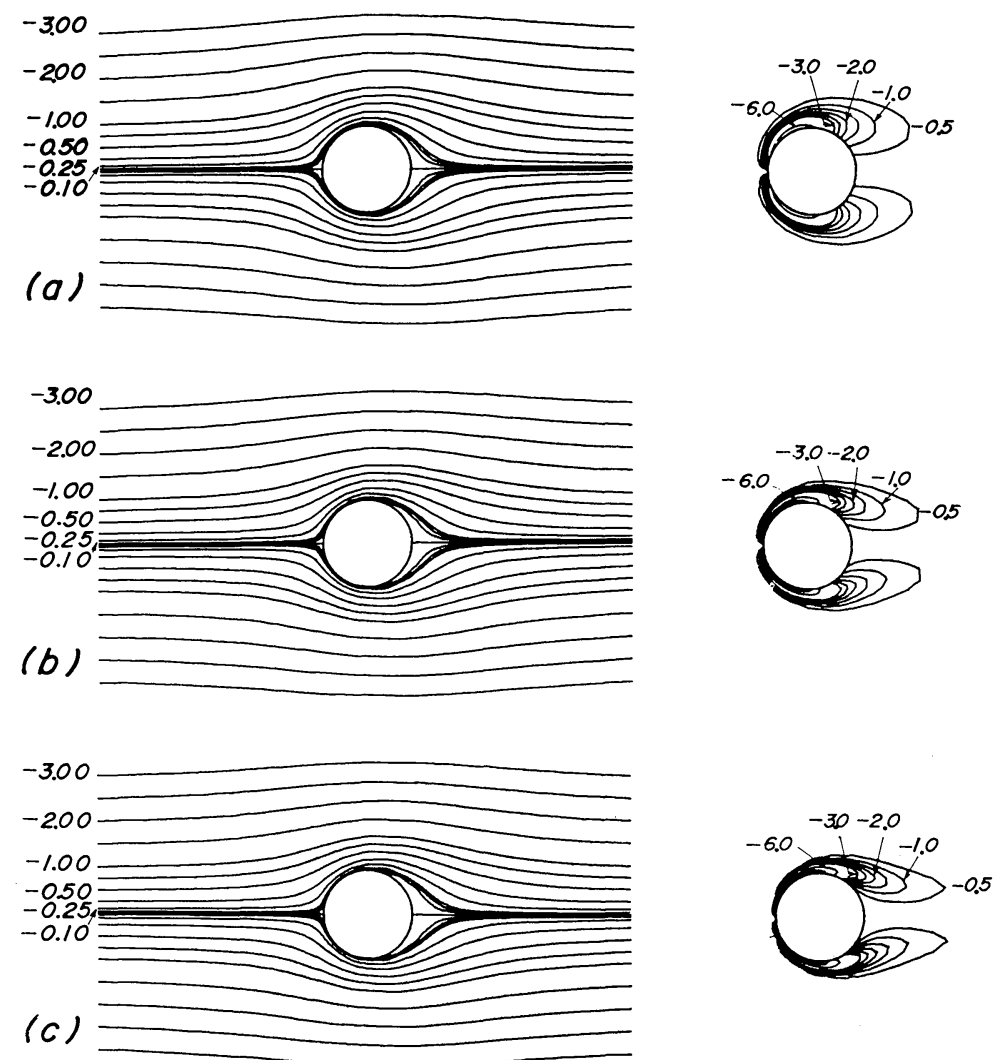

Fig. 4 (a) Streamlines and lines of constant relative vorticity for $\alpha=0.4$ and $R_{e}=40\left(E_{k}=3.9 \times 10^{-3}, \quad R_{0}=1.56 \times 10^{-1}\right)$. (b) As in (a), except that $R_{e}=100$ $\left(E_{k}=6.25 \times 10^{-4}, R_{0}=6.25 \times 10^{-2}\right)$. (c) As in (a), except that $R_{e}=200\left(E_{k}=\right.$ $\left.1.56 \times 10^{-4}, R_{0}=3.13 \times 10^{-2}\right)$.

streamline pattern at such a large value of Reynolds number is similar to that of the low Reynolds number in a non-rotating fluid when $\alpha=1.0$ (Fig. 3c). Another interesting point compared to the non-rotating case is the spindown of standing eddies behind the cylinder (Figs. 3a and 3b). This point is discussed in detail in the later subsection.

Figure 4 shows that the dependence of the numerical results on the Reynolds number dependence is quite weak. Slight changes in the boundary layer occurs only around the cylinder. This is because the lateral diffusion is important only in the vicinity of the cylinder.

It is of interest to compare the length of the standing eddies observed by Boyer and Davies (1982) and that predicted by the present calculation. In Fig. 5, we show schematically the definition of the length of the eddies, which is almost the same as Boyer and Davies (1982) adopted. The length $l$ is defined as the distance from the point $O$ at rear of the cylinder to the point where the separation of the two streamlines, $\Psi= \pm 0.02$, is $\varepsilon$. The value $\varepsilon$ we adopted was $R / 5$, which is identical with that defined by Boyer and Davies (1982). Figure 5 is the plots of the calculated value $l / R$ as a function of $\alpha$ and $R_{e}$. Also shown is the experimental results by Boyer and Davies (1982). It is remarkable that the observed values are well approximated by the numerical results for nearly the same parameters. One of the most pronounced features in Fig. 5 is that the wake length is more sensitive to $\alpha$ than to $R_{e}$. This property is consistent with that demonstrated in Fig. 4. We also note that the wake length decreases 


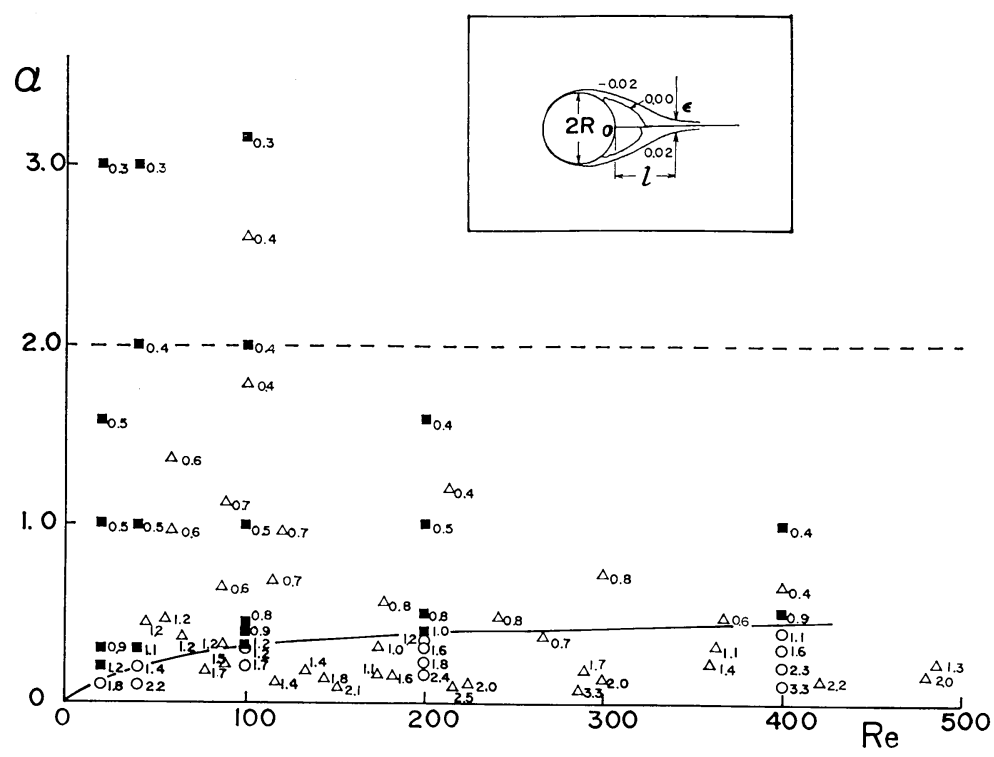

Fig. 5 The comparison between observed lengths of the wake (from Boyer and Davies 1982) and the present numerical results. $\triangle$, laboratory experiment (Boyer and Davies); $\bigcirc$, numerical computation (with separation of boundary layers); $\mathbf{a}$, numerical computation (without separation). The solid line is the sufficient criterion of separation predicted by the present calculation, whereas the dashed line $(\alpha=2)$ is the necessary criterion based on the boundary layer approximation (cf. Walker and Stewartson, 1972).

as $\alpha$ increases. This latter property is consistent with that shown in Fig. 3. Boyer and Davies (1982) adopted the definition that when $l / R<0.5$ the flow is "essentially fully attached". If we adopt the same definition, we may conclude that the separation occurs somewhere between $\alpha=1$ and $\alpha=2$. If we adopt the condition that the velocity gradient normal to the wall vanishes $\left(\partial u_{0} / \partial r=0\right)$ as the definition of the separation, however, our numerical experiments show that the flow around the cylinder does not separate "in a final steady state" even if $l / R$ exceeds unity. The close inspection of some cases $\left(R_{e}=200, \alpha=0.4\right.$, for example) shows that the flow around the cylinder becomes fully attached to the boundary after the steady state is reached (see Fig. 6). This phenomenon is so different from the non-rotating case and suggested the importance of the role of the Ekman friction. The related problem is discussed in Section 5.3.

\subsection{Pressure fields and drag exerted on a cylinder}

Here we evaluate the drag on a cylinder. The total drag is composed of two components. One is the pressure drag $D_{p}$ and the other is the friction drag $D_{f}$. The details of the calculation are shown in Appendix A.

Figure 7 shows the relationship between the total drag coefficient $C_{d}$ and $R_{e}$ for various $\alpha$. As is evident in the figure, $C_{d}$ increases as $\alpha$ increases when $R_{e}$ is fixed. In Fig. 8 we show the $\alpha$-dependence of $C_{p}$ (drag coefficient due to the pressure) and $C_{f}$ (drag coeficicient due to the friction) for $R_{e}=200$. Although both $C_{p}$ and $C_{f}$ increases with $\alpha$, $C_{p}$ is much more sensitive to $\alpha$. This can be understood by checking on Fig. 3. The envelope of the circular cylinder plus spindown eddies changes significantly as $\alpha$ decreases; it becomes more and more similar to an airfoil. Figure 9 shows the pressure distribution around the cylinder for $R_{e}=200$. As 

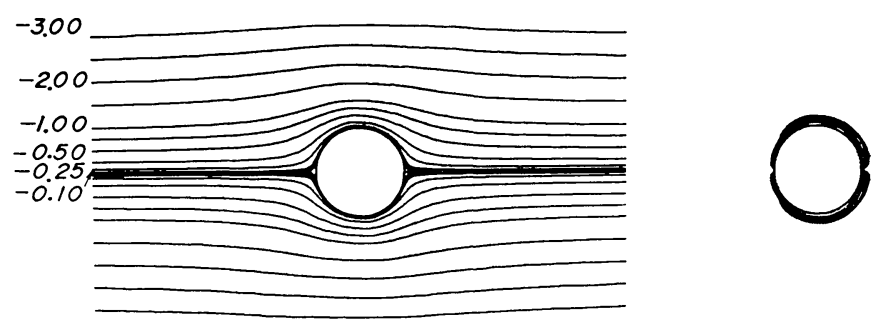

\section{(a) $T=0.0$}
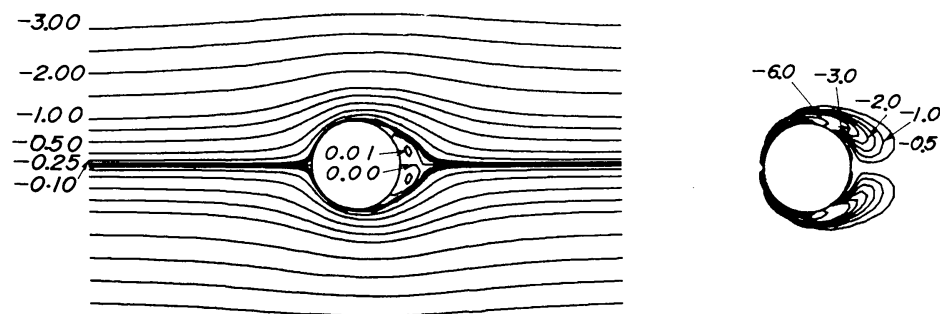

\section{(b) $T=2.0$}
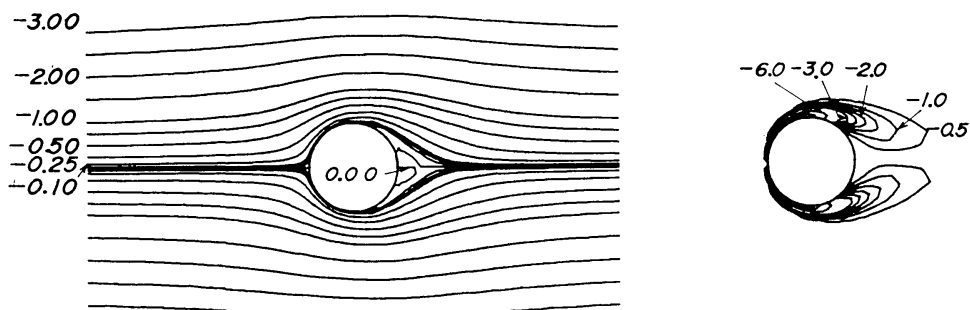

\section{(c) $T=4.0$}
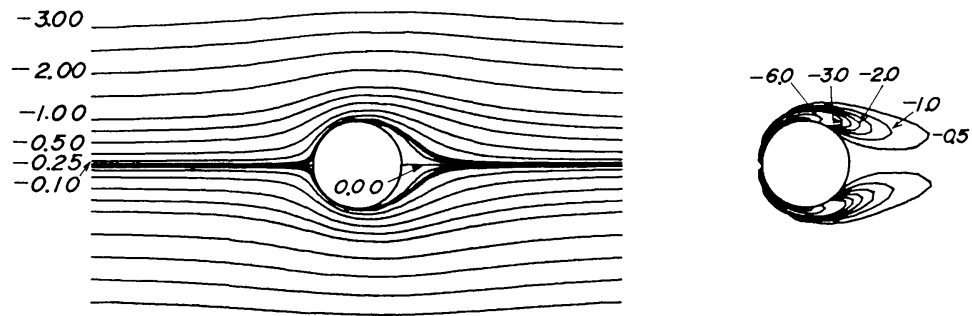

\section{(d) $T=6.0$}

Fig. 6 Time evolution of streamlines and lines of constant relative vorticity for $R_{e}=200$ and $\alpha=0.4 \quad\left(E_{k}=1.56 \times 10^{-4}, R_{0}=3.13 \times 10^{-2}\right)$. The flow separated initially becomes finally attached to the cylinder.

$\alpha$ becomes small, the pressure difference between the forward side and the rear side reduces. Since the additional downstream pressure gradient due to the Ekman friction is reduced with decreasing $\alpha$, the drag due to the pressure difference decreases. This is consistent with the result shown in Fig. 8.
In order to compare our result with that of the nonrotating case $(\alpha=0)$ (cf. Tritton 1959), we show how $C_{d}$ depends on $R_{e}$ in Fig. 7. As $R_{e}$ increases, $C_{d}$ monotonically decreases for a fixed $\alpha$. This tendency is quite similar to the non-rotating case (which corresponds to the case $\alpha=0$ ). However $C_{d}$ becomes large as $\alpha$ increases for the fixed $R_{e}$, 


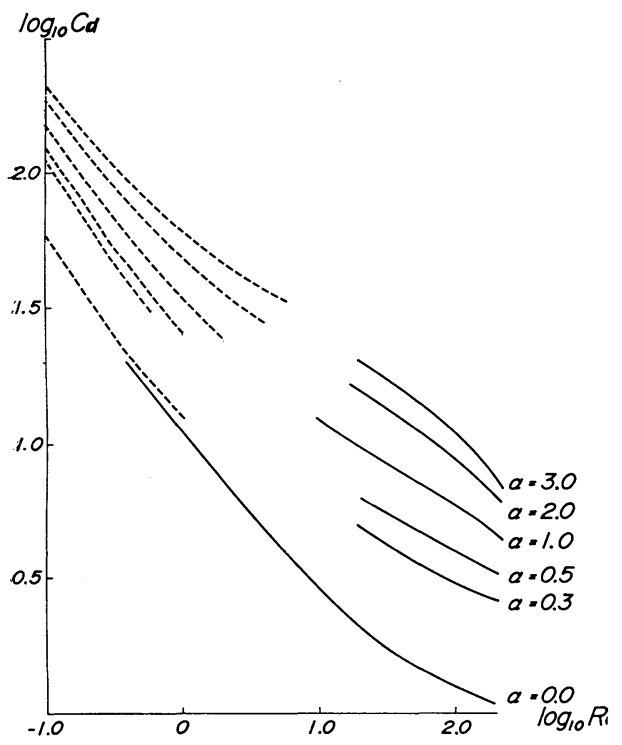

Fig. 7 Plot of $\log _{10} C_{d}$ against $\log _{10} R_{e}$ at dfferent values of $\alpha$. The dashed curve for $\alpha=0$ is the Oseen's drag law. The solid curve for $\alpha=0$ is the experimental one (Tritton 1959). The dashed curves for $a \neq 0$ are based on the modified Stokes's law (see (3.6)). The solid curves for $\alpha \neq 0$ are based on the present numerical results.

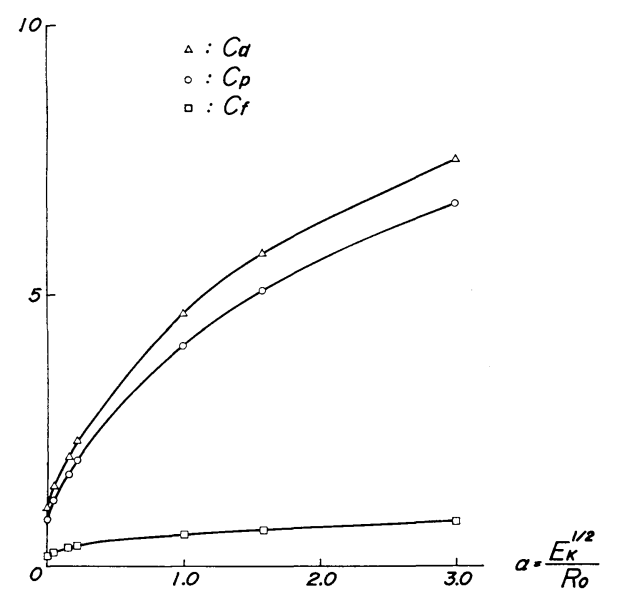

Fig. 8 Plot of the total drag coefficient $C_{d}$, pressure drag coefficient $C_{p}$ and frictional drag coefficient $C_{f}$ against $\alpha$ for $R_{e}=200$.

as mentioned earlier. In other words, $C_{d}$ for the rotating case (which corresponds to the cases $\alpha \neq 0$ ) at a fixed Reynolds number corresponds to $C_{d}$ at the lower Reynolds number for the non-rotating case. This remarkable results is consistent with the description

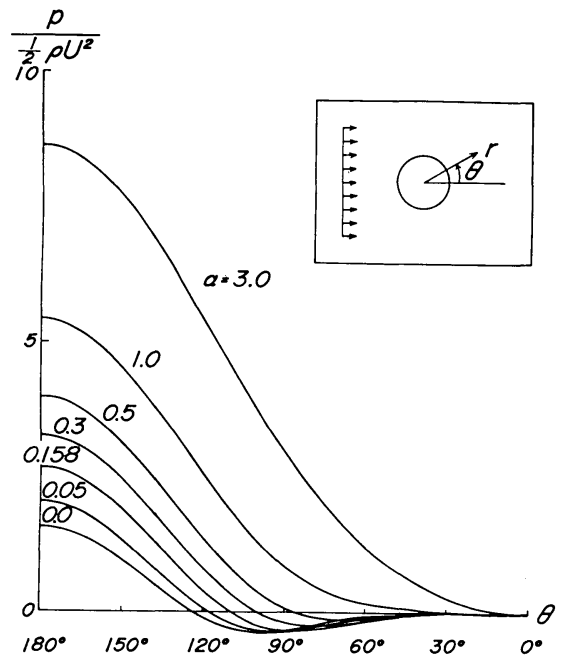

Fig. 9 Pressure distribution on the surface of a circular cylinder for $R_{e}=200$.

(shown in $\$ 5.1$ ) that the streamline pattern at a large Reynolds number in a rotating system is similar to that at a low Reynolds number in a non-rotating system. The dashed lines for $\alpha \neq 0$ in Fig. 7 are due to the modified Stokes's law which is derived in $\S 3$. They are smoothly connected to the numerical results at the moderately large Reynolds number. This is due to the fact that the Stokes's solution is uniformly valid in the rotating system.

\subsection{Spin-down of standing vortices behind the cylinder}

In this section we discuss the evolution of the flow from the initial state under the conditions of (4.4) for $\alpha=0.224$ and $R_{e}=200$. The two eddies behind the cylinder develop until $T=4.0$. After that the eddies spin down and the motion in the eddies become very weak finally. The flow around the cylinder then looks as if it passed an airfoil composed of the cylinder and damped eddies. The above result is extremely different from that of a non-rotating case (see Fig. 2c and Figs. 3a, b).

Figure 10 shows the time evolution of the vorticity balance at a center of the eddy. It is clear that all terms (the unsteady term, the advection term, the Ekman friction term and lateral diffusion term) in Eq.(2.11) are 


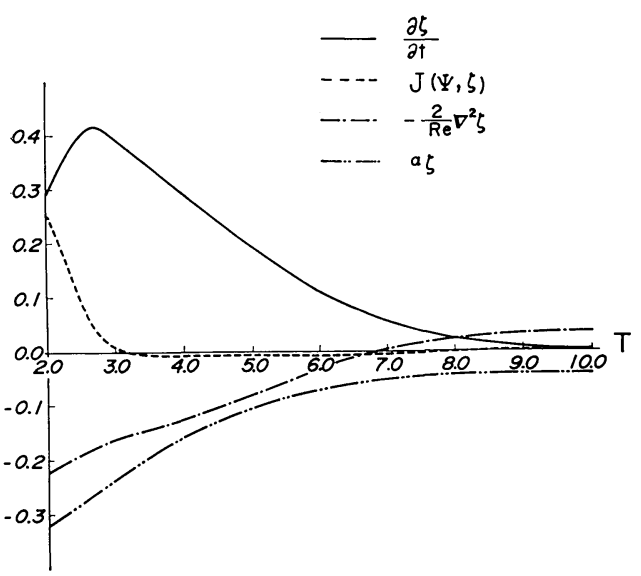

Fig. 10 Relative importance among various terms which appear in the quasi-geostrophic potential vorticity equation (2.11) at a center of the eddy. $\quad R_{e}=200$ and $\alpha=0.224\left(E_{k}=5.0 \times 10^{-4}\right.$, $R_{0}=1.0 \times 10^{-1}$ ).

important at the initial stage. For $3.0<T<7.0$ the main balance is among the unsteady term, the Ekman friction and the lateral diffusion. For $T>8.0$ the motion almost reaches the steady state of which balance is between the weak Ekman friction and the weak lateral diffusion. For $T>3.0$ the nonlinearlity can be neglected and so it is meaningful to compare the simulated spin-down time and the linear spin-down time. Judging from the streamline pattern, the spin-down time is approximately estimated as 3.0. The linear theory shown in Appendix B predicts 2.7 for $\alpha=0.224$ and $R_{e}=200$. The agreement is thus quite good. If we tentatively neglect the lateral friction, the Ekman spin-down time $(1 / \alpha)$ becomes 4.5 , which is much larger than the spin-down time scale estimated by the eddies behind the cylinder. Figure 11 shows the absolute value of the velocity in the eddy behind the cylinder. It is evident that the eddy spins down in the core of the vortex after $T=6.0$. Ingersoll (1969) also discussed the existence of the stagnant core in a inertial Taylor column numerically. The connection between this phenomenon and the classical Prandtl-Batchelor theorem (cf. Batchelor 1956) has recently been discussed by Yamagata and Matsuura (1981).

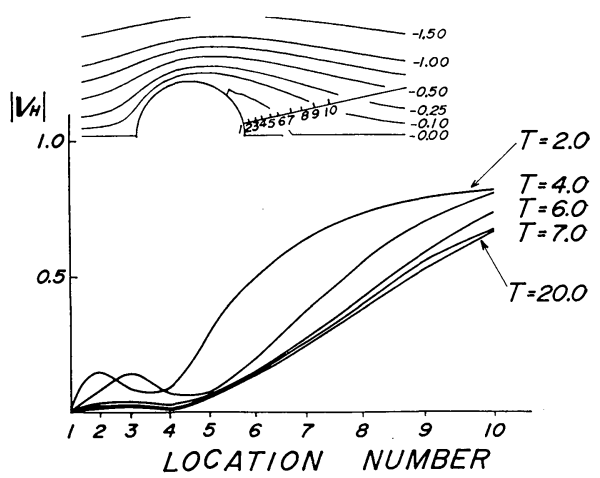

Fig. 11 The magnitude of the absolute velocity at each point aligned in the radial direction across the eddy behind the cylinder.

\section{An asymmetry of a flow pattern}

Boyer (1970) and Boyer and Davies (1982). observed an asymmetry of the flow pattern with respect to the uniform upstream flow direction. Walker and Stewartson (1972) interpreted the asymmetry as the result of the nonlinear drift in the vertical shear layer caused by the divergence (or convergence) in the Ekman layers. Merkine and Solan (1979) demonstrated the asymmetry of the wake analytically by taking such a nonlinear effect into account. It is of interest to see how the nonlinear effect associated with the Ekman friction affects the separation of boundary layers using the grid model.

If we keep $\left(\zeta^{(0)}\left(\partial w^{(1)} / \partial z\right)\right)$ term on the right hand side as $O\left(R_{0}^{2}\right)$ correction in (2.9a), we obtain, instead of Eq.(2.11),

$$
\frac{\partial \zeta}{\partial t}+J(\Psi, \zeta)=-\alpha\left(1+R_{0} \zeta\right) \zeta+\frac{2}{R_{e}} \nabla_{h}^{2} \zeta .
$$

The same equation was recently used by Page (1982) to explain detached shear layers in a sliced cylinder. Notice here that the relative vorticity $\left(R_{0} \zeta\right)$ appears in the term of the Ekman friction. The flow pattern shown in Fig. 12(a) $\left(R_{e}=200, \quad \alpha=1.0\right)$ is quite similar to that in Fig. 3(c) which is solved using Eq. (2.11). Once separation occurs, however, the asymmetry of the flow pattern becomes quite clear as shown in Fig. 12(b) $\left(R_{e}=200\right.$, $\alpha=0.158$ ) (cf. Fig. 3(a)). This is because the effective role of the Ekman friction increases 

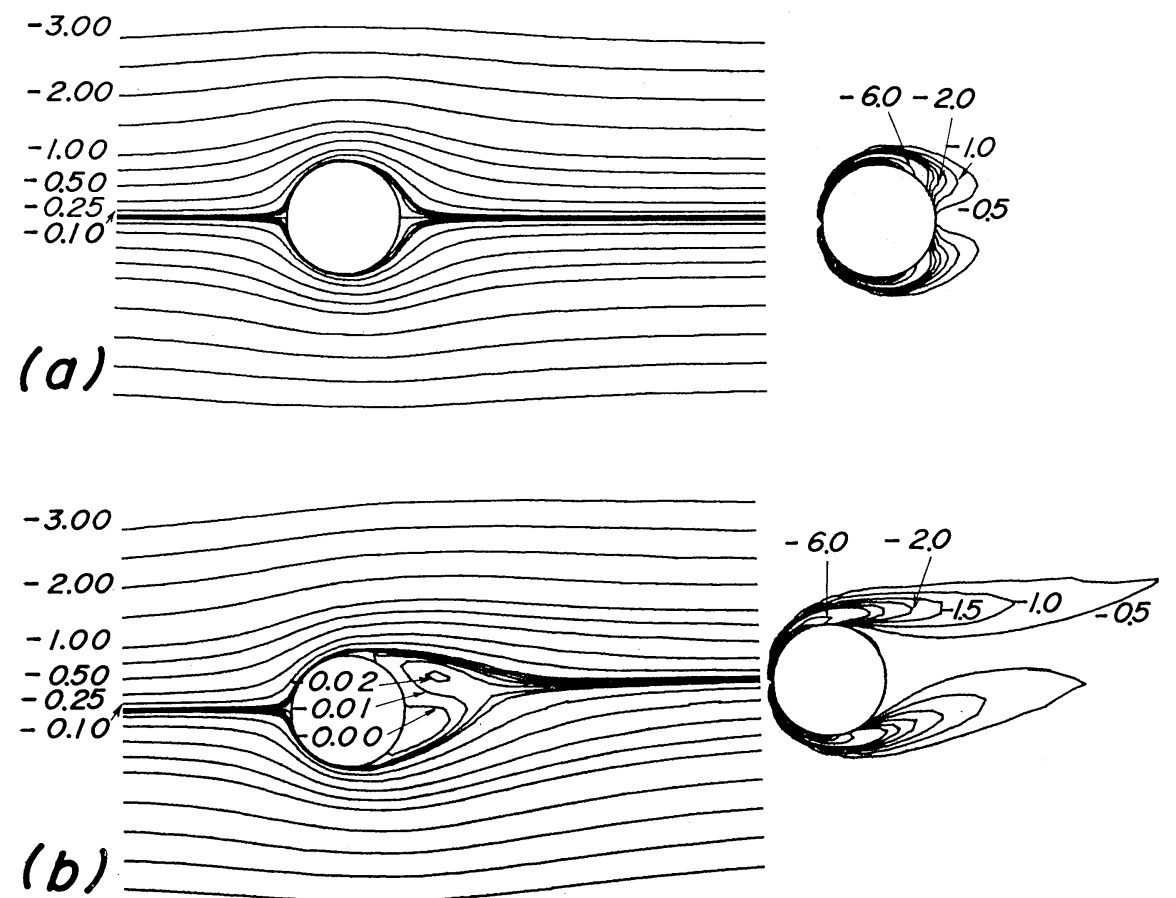

Fig. 12 Streamlines and lines of constant relative vorticity simulated by using (6.1) for $R_{e}=200 . \quad$ (a) $\alpha=1.0\left(E_{k}=2.5 \times 10^{-5}, \quad R_{0}=5.0 \times 10^{-3}\right)$. (b) $\alpha=0.158 \quad\left(E_{k}=1.0 \times 10^{-3}, R_{0}\right.$ $\left.=2.0 \times 10^{-1}\right)$.
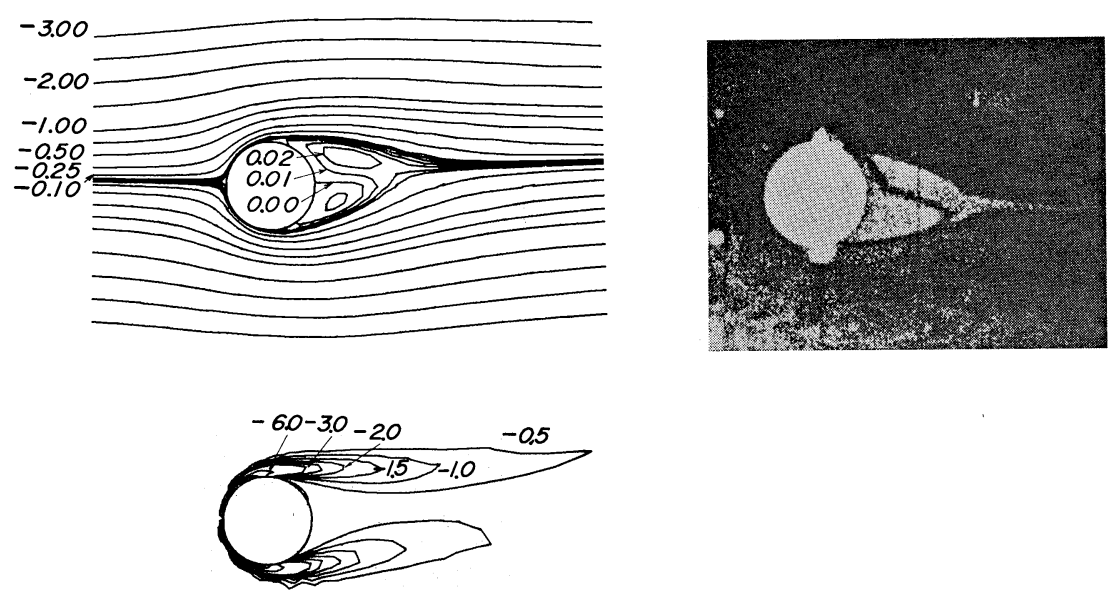

Fig. 13 Streamlines and lines of constant relative vorticity simulated by using (6.1) for $E_{k}=8.6 \times 10^{-4}$ and $R_{0}=2.2 \times 10^{-1}$ (left panel) $\left(R_{e}=256, \alpha=0.133\right.$ ) and streamlines cited from Boyer (1970) (right panel).

on the right hand side of the cylinder facing downstream $(\zeta>0)$ and decreases on the left hand side $(\zeta<0)$. In Fig. 13 we set the parameters equal to Boyer's laboratory experiment. The correspondence between the two pictures is almost exact. This striking result encourages us to use (6.1), although it derivation is somewhat intuitive.

\section{Conclusions}

The viscous flow past a circular cylinder on an $f$-plane has been studied mainly by 
integrating the quasi-geostrophic equation numerically. In summary the main results in response to the problems posed in $\S 1$ are as follows.

(i) The presence of the Ekman friction delays the separation by alleviating the adverse pressure gradient at the surface of the cylinder. In particular, the high Reynolds number flow with the Ekman friction looks like the low Reynolds number flow without the Ekman friction. The numerical flow patterns compare well with those from the experiments.

(ii) The total drag coefficient $C_{d}$ depends on two parameters $R_{e}$ and $\alpha$ where $R_{e}$ is the Reynolds number and $\alpha$ is the ratio of the square root of the Ekman number to the Rossby number. The $R_{e}$-dependence is similar to that of a non-rotating case $(\alpha=0) ; C_{d}$ decreases as $R_{e}$ increases within $20 \leqq R_{e} \leqq 200$. When $R_{e}$ is fixed, $C_{d}$ increases as $\alpha$ increases. This is mainly because the pressure drag coefficient $C_{p}$ increases as $\alpha$ increases. This means that the Ekman friction increases the drag coefficient mainly by increasing the downstream pressure gradient at the surface of the cylinder. This result is consistent with (i).

(iii) The eddies initially formed behind the cylinder (when $R_{e}$ is sufficiently large) spin down finally. The cores of the eddies become almost stagnant due to the Ekman friction. This is entirely different from the case in a non-rotating system.

(iv) The inclusion of a nonlinear effect associated with the Ekman friction well explains the asymmetry observed in the laboratory experiments.

\section{Acknowledgements}

The numerical work was done in 1981 at Kyushu University (RIAM) as a part of T. M's doctoral thesis under the supervision of T.Y.. Final preparation of manuscript was completed by T.Y. while he was a Visiting Scientist in the Geophisical Fluid Dynamics Program at Princeton University, which was supported by NOAA/Princeton University Grant 04-7022-44017. T. Y. is very grateful to Prof. M. Stern for encouragement at the initial stage of the present work, Drs. L. Merkine, M. Uryu, Y. Kurihara, R. Pierrenhumbert, Y. Hayashi, M. Salby and Mr. W-D. Chen for helpful comments, Drs. A. Davies and D. Boyer for helpful correspondence. Thanks also go to Ms. S. Okamoto for figure preparation and typing.

\section{Referencs}

Barcilon, V. 1970: Some inertial modification of the linear viscous theory of steady rotating fluid flows. Phys. Fluid. 13, 537-544.

Batchelor, G.K. 1956: On steady laminar flow with closed streamlines at large Reynolds number. $J$. Fluid Mech, 1, 177-190.

- 1970: An introduction to Fluid Dynamics. Cambridge University Press, London.

Bennetts, D. A. and M. Hocking, 1973: On nonlinear Ekman and Stewartson layers in a rotating fluid. Proc. R. Soc. Lond. A, 333, 469-489.

Boyer, D.L. 1970 : Flow past a right circular cylinder in a rotating frame. J. Basic Engng, 92. 430-436.

- and A. Davies, 1982: Flow past a circular cylinder on a beta-plane. Phil. Trans. R. Soc. Lond, A306, 533-556.

Greenspan, H.P. 1968: The Theory of Rotating Fluid. Cambridge University Press, London.

Hide, R. 1968: On source-sink flows in a rotating fluid. J. Fluid Mech, 32, 737-764.

Ingersoll, A.P. 1969: Inertial Taylor colums and Jupiters great red spot. J. Atoms. Soc, 26, 744752.

Kawaguti, M. and A. Jain, 1966: Numerical study of a viscous fluid flow past a circular cylinder. J. Phys. Soc. Japan, 21, 2055-2063.

Merkine, L. O. and A. Solan, 1979: The separation of flow past a cylinder in a rotating system. J. Fluid Mech, 92, 381-392.

Page, M. A. 1982: A numerical study of detached shear layers in a rotating sliced cylinder. Geophys. Astrophys. Fluid. Dyn, 22, 51-69.

Proudman, J. 1916: On the motion of solids in liquids possessing vorticity. Proc. Roy. Soc. Lond, A92, 408-424.

Stewartson, K. 1957: On almost rigid rotations. J. Fluid Mech, 3, 17-26.

Taneda, S. 1956: Experimental investigation of the wakes behind cylinders and plates at low Reynolds number. J. Phys. Soc. Japan, 11, 302-307.

Taylor, G. I. 1917: Motion of solid in fluid when the flow is not irrotational. Proc. Roy. Soc. Lond. A93, 99.

Tritton, D. J. 1959: Experiments on the flow past a circular cylinder at low Reynolds number. $J$. Fluid Mech, 6, 547-567.

Walker, A. and K. Stewartson, 1972: The flow past a circular cylinder in a rotating frame. ZAMP, 
23, 745-752.

Yamagata, T. 1976: A preliminary study of flows generated by a cylinder moving on a beta-plane. Geophys. Fluid Dynamics Program, Wood Hole Oceanographic Institution, Ref. No. 76-81, 199212.

and T. Matsuura, 1981: A generalization of Prandtl-Batchelor theorem for planetary fluid flows in a closed geostrophic contour. J. Meteor. Soc. Japan, 59, 615-619.

\section{Appendix A}

Drag coefficients

There are two components in the total drag $D$ : pressure drag $D_{p}$ and friction drag $D_{f}$. In order to calculate the pressure distribution over the surface of a cylinder, we use the expression

$$
p(\theta)_{r=1}=\frac{2}{R_{e}} \int_{0}^{\theta}\left(\frac{\partial \zeta}{\partial r}\right)_{r=1} d \theta+\text { const. , }
$$

where $p$ is non-dimensionalized with $2 \rho \Omega U R$. The drag coefficient due to the pressure is given by

$$
C_{p} \equiv \frac{D_{p}}{\rho U^{2} R}=-\int_{0}^{2 \pi} p \cos \theta d \theta .
$$

Notice here that the geostrophic pressure $p^{(0)}$ does not contribute $C_{p}$. Therefore the most important contribution to $C_{p}$ is due to $p^{(1)}$. The rate of strain component $e_{r \theta}$ over surface is expressed as

$$
\left(e_{r \theta}\right)_{r=1}=-\frac{\partial \Psi}{\partial r}+\frac{\partial^{2} \Psi}{\partial r^{2}}-\frac{\partial^{2} \Psi}{\partial \theta^{2}}=(\zeta)_{r=1} .
$$

Thus the drag coefficient due to the friction $C_{f}$ is given by

$$
C_{f} \equiv \frac{D_{f}}{\rho U^{2} R}=-\frac{2}{R_{e}} \int_{0}^{2 \pi}(\zeta)_{r=1} \sin \theta d \theta .
$$

The total drag coefficient $C_{D}$ is just the superposition of the above two components;

$$
C_{D}=C_{p}+C_{f} .
$$

\section{Appendix B}

Estimation of the linear spin-down time

Here we estimate the linear spin-down time. As shown in Fig. 10, the nonlinear advection of the relative vorticity can be neglected after the eddies developed. Then Eq. (2.11) is reduced to

$$
\frac{\partial \zeta}{\partial t}=-\alpha \zeta+\frac{2}{R_{e}} \boldsymbol{\nabla}_{h}^{2} \zeta
$$

Hereafter we tentatively assume that the vortex is axisymmetric. Adopting the transformation

$$
\zeta(r, t)=\hat{\zeta}(r, t) e^{-\alpha t},
$$

and substituting (B2) into (B1), we obtain

$$
\frac{\partial \hat{\zeta}}{\partial t}=\frac{2}{R_{e}}\left(\frac{\partial^{2} \hat{\zeta}}{\partial r^{2}}+\frac{1}{r} \frac{\partial \hat{\zeta}}{\partial r}\right) .
$$

The boundary conditions for $\hat{\zeta}$ are

$$
\left.\begin{array}{l}
\hat{\zeta} \neq \infty \quad \text { at } \quad r=0, \\
\frac{\partial \hat{\zeta}}{\partial r}=0 \quad \text { at } \quad r=l,
\end{array}\right\}
$$

where $l$ is the radius of the eddy. The solution is expressed as

$$
\hat{\zeta}(r, t)=\sum_{m=1}^{\infty} A_{m} J_{0}\left(q_{m} r\right) e^{-\left(2 q_{m}^{2} / R_{e}\right) t} .
$$

where $q_{m} l=(m+(1 / 4)) \pi(m=1,2 \cdots)$. Thus we obtain, for $\zeta$,

$$
\zeta(r, t)=\sum_{m=1}^{\infty} A_{m} J_{0}\left(q_{m} r\right) e^{-\left(\alpha+\left(2 q_{m}^{2} / R_{e}\right)\right) t} .
$$

Therefore the measure of the spin-down time is given by $\left(\alpha+2 q_{1}^{2} / R_{e}\right)^{-1}$. For $\alpha=0.224$ and $R_{e}=200, l \simeq 1.0$ and so $2 q_{1}^{2} / R_{e}=0.154$. Thus we estimate that the spin-down time is approximately 2.7 . 


\title{
$f$-面上の円柱をよぎる粘性流の数值的研究
}

\author{
松 浦 知 徳* ・山 形 俊 男** \\ $*$ 茨城大学工学部 ${ }^{* *}$ 九州大学応用力学研究所
}

$f$ 面上の一様で, 均質な粘性流体中に置かれた 円柱を通過する流れの 数值解を求めた。数值解は Boyer (1970) と Boyer and Davies (1932) の室内実験結果を極めてよく再現し, エクマン摩摖の効果が円柱からの 境界層剥離を遅らせるといら結論を数値的に実証した。これはエクマン摩擦が円柱表面での逆圧力勾配を軽減 するためであることがわかった。初期に円柱背後に形成される双子渦は最終的にスピンダウンする。これらの 渦の中心部は非回転系の場合と異なり, 最終的にほとんど流れのない状態に落ち着く。抵抗係数 $C_{d}$ はレイノ ルズ数 $R_{e}$ と $\alpha$ (エクマン数の $1 / 2$ 乗とロスビー数の比) の 2 つのパラメータに依存する。 $\alpha$ を固定したと き，少なくとも $20 \leqq R_{e} \leqq 200$ では $R_{e}$ が大きくなるにしたがい $C_{d}$ は減少することがわかった。るし $R_{e}$ が一定に保たれていれば， $C_{d}$ は $\alpha$ とともに增加する。新しく導いた回転流体のストークス抵抗則は，小さ なレイノルズ数に対して，数值的に調べた結果とよく一致することがわかった。またエクマン摩擦と結びつい た高次の非線形効果は，境界層剥離が起こるとき，後流域に顕著な非対称性を生みだすことがわかった。この ことも室内実験の結果と良く一致している。 